\title{
Revisão das duas espécies de Tapacura Tibana \& Lopes, 1985 (Diptera: Sarcophagidae: Sarcophaginae)
}

\author{
Cátia Antunes de Mello-Patiu ${ }^{1,3}$ \& Américo da Silva Pereira de Souza Neto ${ }^{1,2}$ \\ Biota Neotropica $v 7(n 1)$ \\ http://www.biotaneotropica.org.br/v7n1/pt/abstract?taxonomic-review+bn02207012007 \\ Recebido em 20/03/06 \\ Versão reformulada recebida em 01/12/06 \\ Publicado em 18/01/07 \\ ${ }^{1}$ Departamento de Entomologia, Museu Nacional - UFRJ, Quinta da Boa Vista, \\ São Cristóvão, Rio de Janeiro, CEP 20940-040 \\ ${ }^{2}$ Estagiário de Iniciação Científica \\ ${ }^{3}$ Autor para correspondência: Catia Antunes de Mello-Patiu, e-mail: camello@acd.ufrj.br
}

\begin{abstract}
Mello-Patiu, C.A. \& Souza Neto, A.S.P. Revision of the two species of Tapacura Tibana \& Lopes, 1985 (Diptera: Sarcophagidae: Sarcophaginae). Biota Neotrop. Jan/Apr 2007 vol. 7, no. 1 http://www.biotaneotropica.org.br/v7n1/pt/abstract?taxonomic-review+bn02207012007 ISSN 1676-0603.

This revision presents a study on external morphology of the species of Tapacura Tibana \& Lopes 1985, especially of the male terminalia. Tapacura includes presently two species: T. mariarum Tibana \& Lopes, 1985 and T. mexicana Lopes, 1988, which were related to Peckiamyia Dodge, Retrocitomyia Lopes and Sinopiella Lopes \& Tibana in the original description. Redescriptions, illustrations and a broadest generic diagnosis are presented. A comparison between the Tapacura species and those of the related genera has showed that Tapacura is more morphologically similar to Peckiamyia, especially because both have the third costal section of the wing with ventral setulae, male mid femur without ctenidium and a very reduced and pigmented aedeago.

Keywords: morphology, terminalia, taxonomy, Sarcophagidae.

\section{Resumo}

Mello-Patiu, C.A. \& Souza Neto, A.S.P. Revisão das duas espécies de Tapacura Tibana \& Lopes, 1985 (Diptera: Sarcophagidae: Sarcophaginae). Biota Neotrop. Jan/Apr 2007 vol. 7, no. 1 http://www.biotaneotropica.org.br/v7n1/pt/abstract?taxonomic-review+bn02207012007 ISSN 1676-0603.

Esta revisão apresenta um estudo da morfologia externa das espécies de Tapacura Tibana \& Lopes 1985, especialmente da terminália masculina. Tapacura inclui atualmente duas espécies: T. mariarum Tibana \& Lopes, 1985 e T. mexicana Lopes, 1988, que foram relacionados a Peckiamyia Dodge, Retrocitomyia Lopes e a Sinopiella Lopes \& Tibana na descrição original. São apresentadas redescrições, ilustrações e uma diagnose genérica mais ampla. Uma comparação entre as espécies de Tapacura e aquelas dos gêneros relacionados tem mostrado que Tapacura é mais similar morfologicamente a Peckiamyia, especialmente porque ambos têm o $3^{\circ}$ setor costal da asa com pequenas cerdas ventrais, o fêmur médio do macho sem ctenídio e o edeago muito reduzido e pigmentado.
\end{abstract}

Palavras-chave: morfologia, terminália, taxonomia, Sarcophagidae. 


\section{Introdução}

A família Sarcophagidae é representada na região neotropical por cerca de 800 espécies (Pape 1996). Os sarcofagídeos são moscas de morfologia externa bastante uniforme e a distinção de gêneros e espécies têm sido baseada, principalmente, na morfologia da terminália masculina. Entretanto, a grande diversidade morfológica das estruturas genitais dificulta evidenciar as homologias e, conseqüentemente, delimitar grupos monofiléticos, o que têm provocado profundas diferenças de opinião quanto aos limites genéricos (Lopes 1982, Pape 1996). Neste contexto, estudos revisionais, com observações detalhadas da terminália, têm fornecido excelentes argumentações para futuros estudos que conduzam ao desenvolvimento de uma classificação taxonômica mais consistente, especialmente dentre os Sarcophaginae neotropicais (Lopes 1991a, b, Pape 1994, Mello 1996, Mello-Patiu \& Pape 2000, Guimarães 2004).

Tapacura Tibana \& Lopes, 1985 foi um gênero erigido para abrigar uma única espécie, T. mariarum, e foi definido como sendo composto de moscas pequenas, cujos machos apresentam fêmur médio sem ctenídio, edeago pequeno e esclerosado com vesica membranosa, apódema do ducto ejaculatório grande e glans com estilo mediano composto de um par de hastes tão desenvolvidas quanto os estilos laterais. Posteriormente, Lopes (1988) descreveu outra espécie, T. mexicana, ressaltando a presença de um par de placas protetoras na glans. Tibana \& Lopes (1985) relacionaram Tapacura a Peckiamyia Dodge, 1966 e a Retrocitomyia Lopes, 1982 pelo edeago reduzido e a Sinopiella Lopes \& Tibana, 1982 pelo grande apódema ejaculatório. Comparando-se as descrições desses gêneros, além das descrições das duas espécies de Tapacura, percebe-se que deve haver certa confusão com relação à delimitação e interpretação da vesica, do estilo mediano e da estrutura que foi denominada haste ou placa protetora. Essa dificuldade deve-se, principalmente, ao fato dessas espécies possuírem um edeago pequeno, muito esclerosado e negro, o que dificulta a visualização e a delimitação de suas estruturas internas, que servem de base para a taxonomia dos Sarcophagidae. Portanto, torna-se necessária uma revisão detalhada da morfologia das duas espécies, com ênfase na terminália, fornecendo dados para uma posterior comparação com os gêneros relacionados.

\section{Material e Métodos}

O material utilizado neste estudo pertence à coleção do Museu Nacional-UFRJ, Rio de Janeiro (MNRJ). A relação do material examinado encontra-se abaixo de cada descrição, incluindo procedência, data de coleta e coletor.

Os espécimens examinados foram analisados e descritos quanto à morfologia externa e quetotaxia. Suas terminálias foram dissecadas e preparadas segundo o método usual, como descrito por Mello (1996).

A terminologia utilizada para a morfologia geral foi aquela aplicada por McAlpine (1981) e para as estruturas do edeago utilizou-se os termos comumente usados pelos especialistas nos grupos, conforme apresentado em Mello-Patiu \& Pape (2000).

As terminálias dissecadas foram montadas entre lâmina e lamínula com glicerina e desenhadas através de microscópio estereoscópico Wild M5 e microscópio composto Zeiss MC-80, providos de câmara clara. Os desenhos foram feitos a nanquim, sobre papel vegetal. Posteriormente, as terminálias foram depositadas em microtubos com glicerina e esses presos aos alfinetes dos exemplares correspondentes.

\section{Resultados}

\section{Gênero Tapacura Tibana \& Lopes, 1985}

\author{
Tapacura Tibana \& Lopes, 1985: 195. Espécie-tipo \\ Tapacura mariarum Tibana \& Lopes, 1985 (desig. orig.)
}

Diagnose: Moscas pequenas. Cabeça com placa frontorbital, parafaciália e órbita ocular posterior com polinosidade prateada. Tórax com cerdas acrosticais pré-suturais sem diferenciação, 3 dorsocentrais pós-suturais e apicais escutelares bem desenvolvidas; parede pósalar pilosa. Asas com célula r $4+5$ aberta e $3^{\circ}$ setor costal com cerdas na parte ventral. Machos com fêmur médio sem ctenídio, edeago reduzido, fortemente esclerosado e enegrecido, distifalo separado e articulado com o basifalo, com margens laterais dobradas para a região ventral, encobrindo a base dos estilos, apódema do ducto ejaculatório muito grande, vesica pequena e largamente membranosa, placa apical pequena, estilo mediano alongado, com uma abertura mediana na forma de tubo e com um par de placas voltadas para a face ventral do edeago, estilos laterais bem desenvolvidos. Fêmeas com tergito 6 dividido e esternito genital membranoso.

Etimologia: O nome Tapacura foi dado por Tibana \& Lopes, 1985 em alusão a Estação Ecológica de Tapacurá, Pernambuco, local de coleta do holótipo de T. mariarum, espécie-tipo do gênero.

As espécies aqui estudadas, Tapacura mariarum e T. mexicana, são táxons válidos e diferentes, com a forma e a organização do edeago, dos estilos e do esternito 5 bastante peculiares. Isso nos leva a concordar com Tibana \& Lopes (1985) de que se trata de um gênero distinto dos demais, especialmente pela configuração do estilo mediano, que se apresenta composto por um par de placas esclerosadas laterais com uma estrutura tubular central.

As duas espécies de Tapacura podem ser distinguidas entre si, principalmente, pela configuração das estruturas da terminália masculina, conforme a chave abaixo:

1. Epândrio 2 vezes o tamanho do sintergosternito $7+8$, cerco reto em vista lateral, surstilo em forma de clava, estilos laterais com base dobrada (BRASIL, Pernambuco)------------------.Tapacura mariarum Tibana \& Lopes

1'. Epândrio menor que o dobro do tamanho do sintergosternito $7+8$, cerco levemente sinuoso em vista lateral, surstilo arredondado e pequeno, estilos laterais com base alongada para cima (MÉXICO, Baja Califórnia Sur)-------------------- Tapacura mexicana Lopes.

\section{Tapacura mariarum Tibana \& Lopes, 1985}

Tapacura mariarum Tibana \& Lopes, 1985: 196-198; Lopes, 1988: 137. Localidade-tipo: Estação Ecológica Tapacurá, Pernambuco, Brasil

Macho: comprimento total $=5 \mathrm{~mm}$.

Cabeça: Placa frontorbital, parafaciália e órbita ocular posterior com polinosidade prateada (às vezes, amarelo-avermelhada), placa frontorbital com uma série de pequenas cerdas da região superior até o nível do pedicelo; parafaciália com pequenas cerdas ao longo da órbita ocular (mais desenvolvidas inferiormente), linha frontal preta em toda a sua extensão, fronte (no nível das cerdas ocelares) cerca de $3,5 \mathrm{x}$ menor que a largura da cabeça, 5 cerdas frontais convergentes (com praticamente o mesmo tamanho, sendo a $1^{\text {a }}$ superior pouco desenvolvida), cerda frontorbital proclinada ausente e reclinada bem desenvolvida, cerda vertical interna bem desenvolvida e a externa não diferenciada dos cílios pós-oculares (sendo estes menores que as ocelares), cerdas ocelares tão desenvolvidas quanto às frontais, 
parte posterior da cabeça cinzenta com polinosidade prateada e cerdas pretas, gena preta com intensa polinosidade prateada e com a maioria das cerdas claras, parafaciália $2 x$ menor do que a distância entre as vibrissas, antenas castanho-escuras, de comprimento total cerca de $90 \%$ da distância até as vibrissas, flagelo $3 \mathrm{x}$ maior que o pedicelo e arista longa e plumosa na metade basal, palpos castanho-escuros.

Tórax: Castanho-escuro com polinosidade cinzenta. Cerdas acrosticais pré-suturais sem diferenciação e 1 pós-sutural, dorsocentrais: $2+3$, intralares: $2+2$, supralares: 2 (a anterior muito menor) + 3 , pós-pronotais: 3 , pós-alares: 2 , parede pós-alar com cerdas; apicais escutelares: 2, subapicais escutelares: 2 , basal escutelar: 1 , meron: 5 (em série), catepisterno: 3 (quase ao mesmo nível), notopleurais: 2, anepimerais: 2, proepimeral:1. Asas hialinas, $\mathrm{R}_{1}$ com cerdas na metade basal; $\mathrm{R}_{4+5}$ com cerdas na metade basal da distância entre a base e a nervura transversal $\mathrm{r}-\mathrm{m}$, célula $\mathrm{r} 4+5$ aberta; $3^{\circ}$ setor costal com cerdas na parte ventral. Pernas castanho-escuras; fêmur 2 com 1 cerda mediana ântero-ventral, 2 cerdas mediana na face anterior, 2 cerdas pré-apicais posteriores; ctenídio ausente; fêmur 3 com 1 cerda longa ventral pré-apical, uma série de cerdas ântero-dorsais do meio até o ápice, 1 cerda pré-apical dorsal e 1 pré-apical posterior; tíbia

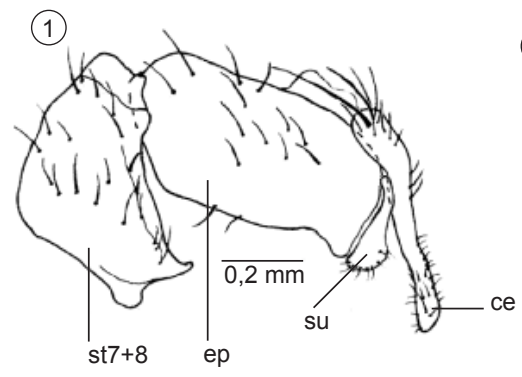

(2)
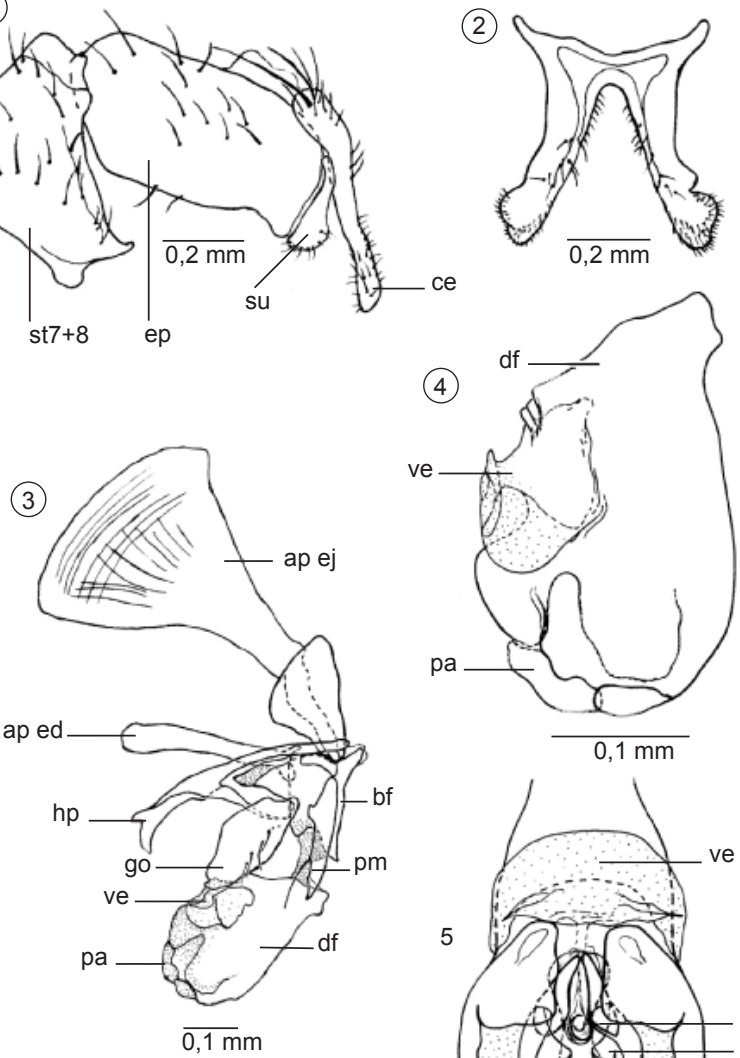

\section{(4)}

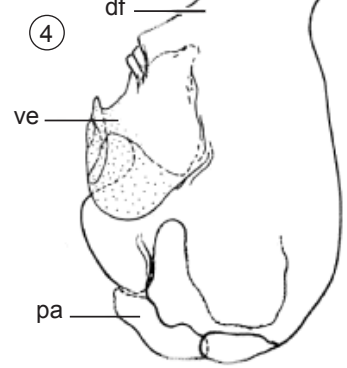

$0,1 \mathrm{~mm}$

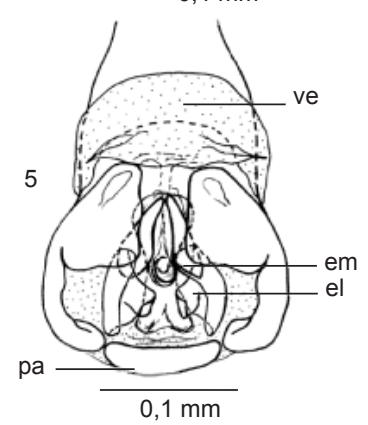

Figuras 1-5. Tapacura mariarum Tibana \& Lopes, macho. 1) Sintergosternito 7+8, epândrio, cerco e surstilo, vista lateral; 2) esternito 5, vista ventral; 3) Edeago e estruturas associadas, vista lateral; 4) Ápice do edeago, vista lateral; e 5) Ápice do edeago, vista ventral.

Figures 1-5. Tapacura mariarum Tibana \& Lopes, male. 1) Syntergosternite $7+8$, epandrium, cercus e surstylus, lateral view; 2) sternite 5, ventral view; 3) Aedeagus e associated structures, lateral view; 4) Aedeagal apex, lateral view; and 5) Aedeagal apex, ventral view.
3 com 1 cerda mediana na margem ântero-ventral; 3 cerdas na margem ântero-dorsal, sendo uma na base, outra no meio e a terceira no ápice; 3 cerdas na margem póstero-dorsal, na mesma posição das ântero-dorsais.

Abdome: Castanho com polinosidade cinzento-amarelada, um pouco mais amarelada no tergito 5; tergito 4 com 1 par de cerdas medianas marginais desenvolvidas e 2 pares de cerdas laterais marginais; esternito 5 profundamente fendido, com braços levemente divergentes e ápices arredondados e pilosos (Figura 2).

Terminália: Castanho-avermelhada, sintergosternito 7+8 sem cerdas apicais desenvolvidas e epândrio apresentando 3 pares de cerdas diferenciadas das cerdas de revestimento, com cerca de $2 \mathrm{x}$ o comprimento do sintergosternito (Figura 1); cerco reto com cerdas curtas no ápice (Figura 1); surstilo em forma de clava (Figura 1); apódema do ducto ejaculatório muito grande (Figura 3); gonópodo curto e largo, com uma série de pequenas cerdas (Figura 3); parâmero com ápice pontiagudo (Figura 3); edeago apresentando basifalo separado do distifalo, distifalo muito esclerosado e pigmentado, com as margens laterais da região próxima a vesica dobrando-se sobre a base dos estilos (Figuras 3, 4 e 5), placa apical pequena e separada do distifalo (Figuras 3, 4 e 5), vesica pequena e membranosa (Figuras 4 e 5), estilos laterais com base dobrada, estilo mediano alongado, com um tubo central ladeado por um par de placas cujo comprimento atinge a sua porção mediana (Figura 5).

Etimologia: O epíteto específico, mariarum, foi dado com referência ao nome das coletoras, Profa. Maria do Carmo Leal e Maria Helena Costa.

Material examinado: BRASIL, Pernambuco, Estação Ecológica de Tapacurá, 1 đิ , holótipo, 16.IX.1980, M.C. Leal \& M.H. Costa; Ceará, Pacatuba, 1 đ̋ , 23.VII.1983 (em Pomacea), C. D. Freitas e N. C. Hime.

\section{Tapacura mexicana Lopes, 1988}

Tapacura mexicana Lopes, 1988:135-137. Localidade-tipo: Isla San José, Baja California Sur, México

Macho: comprimento total 3,5-5,5 mm. Difere de T. mariarum pelos seguintes caracteres: fronte cerca de $3 \mathrm{x}$ menor que a largura da cabeça, gena preta com pouca polinosidade prateada, com cerdas claras e algumas poucas cerdas pretas perto da vibrissa, parafaciália 4x menor do que a distância entre as vibrissas, antenas com comprimento total cerca de $95 \%$ da distância até as vibrissas, flagelo aproximadamente $4 \mathrm{x}$ maior que o pedicelo, cerdas supralares: $1+0$, cerdas basais escutelares: 2 , meron: $3-5$ (em série), catepisterno: 2 (em série), nervura R1 nua; fêmur 2 com 1 cerda mediana na face anterior, esternito 5 profundamente fendido, com braços bastante divergentes e ápices arredondados, formando dois lóbulos pilosos (Figura 7). sintergosternito $7+8$ com leve polinosidade cinzaamarelada, com pequenas cerdas esparsas e epândrio com dois a três pares de pequenas cerdas diferenciadas das cerdas de revestimento, um pouco mais longo que o sintergosternito (Figura 6); cerco levemente sinuoso com cerdas curtas no ápice (Figura 6); surstilo arredondado e pequeno; gonópodo curto, alargado e com pequenas cerdas (Figura 8); parâmero com ápice pontiagudo (Figura 8); edeago, incluindo basifalo, muito esclerosado e pigmentado, apresentando basifalo separado do distifalo, distifalo com as margens laterais da região próxima a vesica dobrando-se sobre a base dos estilos (Figuras 8, 9 e 10), placa apical pequena e separada do distifalo (Figuras 8, 9 e 10), vesica pequena e membranosa (Figuras 9 e 10), estilos laterais com base alongada para cima, estilo mediano alongado, com um tubo central ladeado por um par de placas com o mesmo comprimento do estilo mediano (Figura 10). 


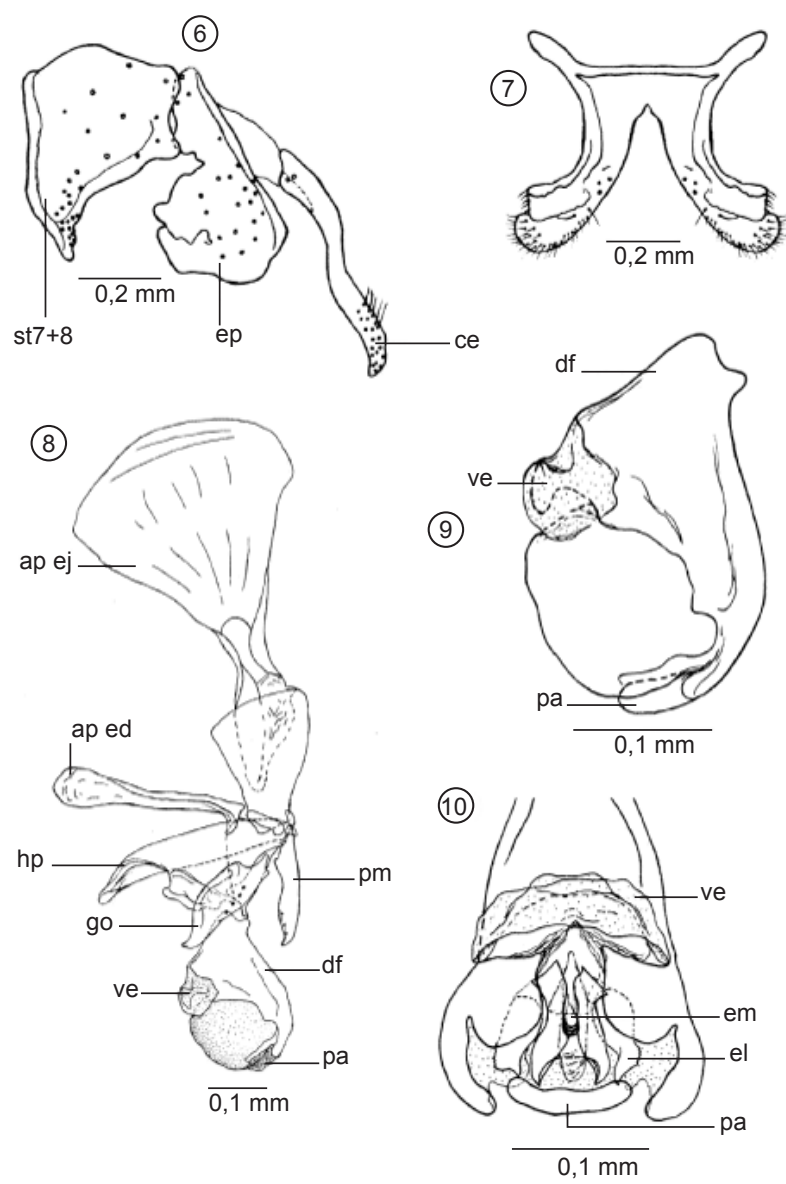

Figuras 6-10. Tapacura mexicana Lopes, macho. 6) Sintergosternito 7+8, epândrio, cerco e surstilo, vista lateral; 7) esternito 5, vista ventral; 8) Edeago e estruturas associadas, vista lateral; 9) Ápice do edeago, vista lateral; e 10) Ápice do edeago, vista ventral.

Figures 6-10. Tapacura mexicana Lopes, male. 6) Syntergosternite 7+8, epandrium, cercus e surstylus, lateral view; 7) sternite 5, ventral view; Figure 8) Aedeagus e associated structures, lateral view; 9) Aedeagal apex, lateral view; and 10) Aedeagal apex, ventral view.

Etimologia: O epíteto específico, mexicana, é alusivo ao país onde foi coletado o holótipo.

Material examinado: MÉXICO, Baja California Sur, Isla San José, 1ठ, Parátipo (“mangrove”, armadilha Malaise), 10-11.IV.1974, J.T. Doyen; Punta Ostiones, 1ठð, 8-9.IV.1974, J. T. Doyen.

\section{Agradecimentos}

A Fundação Carlos Chagas Filho de Amparo à Pesquisa do Estado do Rio de Janeiro - FAPERJ (Proc. $n^{\circ}$ E-26/ 170.119/2004) pelo auxílio financeiro.

\section{Referências Bibliográficas}

DODGE, H.R. 1966. Some new or little-known Sarcophagidae (Diptera) with a review of the genus Oxysarcodexia. Ann. Entomol. Soc. Am. 59:674-701.
GUIMARÃES, H.J.L., 2004. Redescrição dos machos de dez espécies neotropicais de Ravinia Robineau-Desvoidy, 1863 (Diptera, Sarcophagidae). Arquivos do Museu Nacional 62: 45-66.

LOPES, H.S. 1982. The importance of the mandible and clypeal arch of the first instar larvae in the classification of the Sarcophagidae (Diptera). Rev. Bras. Entomol. 26:293-326.

LOPES, H.S. 1985. Descriptions of six new species of Retrocitomyia Lopes (Diptera, Sarcophagidae). Bol. Mus. Nac. N. S. Zool. 309:1-8.

LOPES, H.S. 1988. Notes on neotropical Sarcophagidae (Diptera) with descriptions of a new genus and five new species. Rev. Bras. Biol. 48:127-137.

LOPES, H.S. 1991a. Third contribution to the knowledge of the genus Lepidodexia Brauer \& Bergenstamm (Diptera, Sarcophagidae). Rev. Bras. Biol. 51:571-583.

LOPES, H.S. 1991b. On Johnsonia (Diptera, sarcophagidae) with descriptions of twelve new species. An. Acad. Brasil. Ciênc. 63:59-84.

LOPES, H.S. \& FERRAZ, M.V. 1991. A new species of Sinopiella (Diptera, Sarcophagidae) from Brasília, DF, Brazil. Mem. Inst. Oswaldo Cruz 86:103-105.

LOPES, H.S. \& TIBANA, R. 1982. Sarcophagid flies (Diptera) from SINOP, state of Mato Grosso, Brazil. Mem. Inst. Oswaldo Cruz 77:285-298.

MCALPINE, J.F. 1981. Morphology and terminology - adults. In Manual of Neartic Diptera (McAlpine et al. eds), Research Branch Agriculture Canada, Ottawa, v. 1, p. 9-63.

MELLO, C.A. 1996. Revisão do gênero Farrimyia Dodge, 1965 (Diptera, Sarcophagidae)-Parte I. Rev. Bras. Biol. 56:459-471.

MELLO-PATIU, C.A. \& PAPE, T. 2000. Definitions of Dexosarcophaga Townsend 1917 and Sarcofahrtiopsis Hall 1933, including two new species and a redescription of Sarcofahrtiopsis cuneata (Townsend 1935) (Diptera: Sarcophagidae). Bol. Entomol. Venez. 15:181-194.

PAPE, T. 1994. The world Blaesoxipha Loew, 1861 (Diptera, Sarcophagidae). Ent. Scand. Suppl. 45:1-247.

PAPE, T. 1996. Catalogue of the Sarcophagidae of the World (Insecta: Diptera). Memoirs on Entomology, International 8. Associated Publishers, Gainesville.

TIBANA, R. \& LOPES, H.S. 1985. On Brazilian Sarcophagidae (Diptera) with description of two new genera and four new species. Rev. Bras. Entomol. 29:189-198.

Titulo: Revisão das duas espécies de Tapacura Tibana \& Lopes, 1985 (Diptera: Sarcophagidae: Sarcophaginae).

Autores: Mello-Patiu, CA e Souza Neto, ASP

Biota Neotropica, Vol.7 (número 1): 2007

http://www.biotaneotropica.org.br/v7n1/pt/abstract? taxonomic-review+bn02207012007

Recebido em 20/03/06 - Versão reformulada recebida em 01/12/06 - Publicado em 18/01/07

\section{ISSN 1676-0603}

